Int. J. Dev. Biol. 57: 153-157 (2013)

doi: $10.1387 / \mathrm{ijdb} .130141 \mathrm{jo}$

\title{
Patient with two secondary somatic-type malignancies in a late recurrence of a testicular non-seminoma: illustration of potential and flaw of the cancer stem cell therapy concept
}

\author{
J.WOLTER OOSTERHUIS*,1,\#, SUZANNE H.P. PEETERS ${ }^{2, \#, ~ V I N C E N T ~ T . H . B . M . ~ S M I T ~}{ }^{3}$, HANS STOOP', \\ LEENDERT H.J. LOOIJENGA ${ }^{1}$, HENK W. ELZEVIER ${ }^{2}$ and SUZANNE OSANTO ${ }^{4}$ \\ ${ }^{1}$ Department of Pathology, Erasmus University Medical Center, Daniel den Hoed Cancer Center, Rotterdam, The \\ Netherlands, ${ }^{2}$ Department of Urology, ${ }^{3}$ Department of Pathology and ${ }^{4}$ Department of Clinical Oncology, Leiden \\ University Medical Center, The Netherlands.
}

\begin{abstract}
Here, we report the case of a patient with a non-seminoma of the left testicle, with an intestinal-type adenocarcinoma and a low grade leiomyosarcoma in a late recurrence 19 years after initial diagnosis. The history of the patient, alive with disease 21 years after initial treatment, illustrates the potential and flaw of the cancer stem cell therapy concept. In addition, it is proposed that residual mature teratoma can be regarded as normalization of cancer due to embryonic patterning, and the development of a secondary somatic-type malignancy as failure of normalization.
\end{abstract}

KEY WORDS: case report, residual mature teratora, secondary non-germ cell malignancy, cisplatin, chemotherapy

\section{Case report}

A 28-year-old male presented in May 1990 with a painful swelling in his left testicle. There were no other symptoms and the past history was unremarkable. Scrotal examination revealed a firm and slightly tender mass in the left testis. On ultrasound it was an inhomogeneous hypo-echogenic distinct lesion with a largest dimension of $2.5 \mathrm{~cm}$.

Blood tests showed a normal lactate dehydrogenase (LDH1) $174 \mathrm{U} / \mathrm{L}$ (normal range, 100 to $248 \mathrm{U} / \mathrm{L}$ ) and beta-human chorionic gonadotropin (B-HCG) 4 (normal range, 0-5 U/L) and a slightly elevated alpha-fetoprotein (AFP) 13 (normal range, 0-10 U/L). A CT-scan showed no abnormalities of thorax, abdomen, and pelvis. Inguinal orchidectomy was performed under the clinical diagnosis of a non-seminomatous germ cell tumor (non-seminoma).

Grossly the orchidectomy specimen showed a testis with a soft, inhomogeneous, reddish solid mass measuring $2.5 \times 2.1 \times 2.1 \mathrm{~cm}$. Histologically the tumor was a mixed non-seminoma with large areas of necrosis. Surrounded by tumor was a focus of intratubular non-seminoma consisting of necrotic tumor tissue. Morphologically intact tumor tissue contained about $50 \%$ embryonal carcinoma (positive for OCT3/4 and SOX2), 45\% mature teratoma, 5\% yolk sac tumor (positive for AFP), and scattered trophoblastic giant cells (positive for HCG). The teratoma component consisted of small glands and cysts, partly lined by cuboidal and intestinal epithelium, focally with overlapping nuclei, and relatively large areas of mesenchymal tissue, amongst others consisting of cKIT-positive gastro-intestinal-stromal tissue and a, desmin-positive, smooth muscle component. None of the teratoma components fulfilled the criteria of a secondary somatic-type malignancy (synonyms: secondary non-germ cell malignancy; teratoma with malignant transformation) as defined in the WHO-classification: atypia, expansive (>1 LPF) and invasive growth (Woodward et al., 2004). Remaining parenchyma showed carcinoma in situ (CIS, synonym IGCNU). There was extensive angio-invasive growth into lymphatics (CD31-weak to negative and D2-40-positive), of the embryonal carcinoma component only, as usual (Ulbright et al., 1997). In fact all stages of progression from CIS to angio-invasiveness could be demonstrated histologically (Fig. 1). The tumor was confined to the testis; no invasion of the rete testis; the surgical margin of the spermatic cord was free of tumor. The serum level of AFP normalized post-operatively. Because of the staging as a pT1 cNO M0, S0 NSGCT of the testis, the patient was given no further treatment, and kept in follow-up according to the wait-and-see policy in an

Abbreviations used in this paper: AFP, alpha fetoprotein; CIS, carcinoma in situ; HGC, human chorion gonadotropin; LDH, lactate dehydrogenase; RPLND, retroperitoneal lymph node dissection.

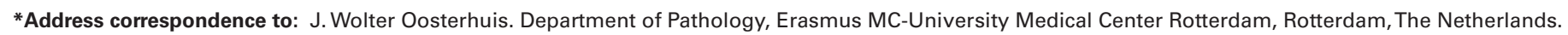
e-mail: j.w.oosterhuis@erasmusmc.nl
}

Final, author-corrected PDF published online: 5 June 2013. 

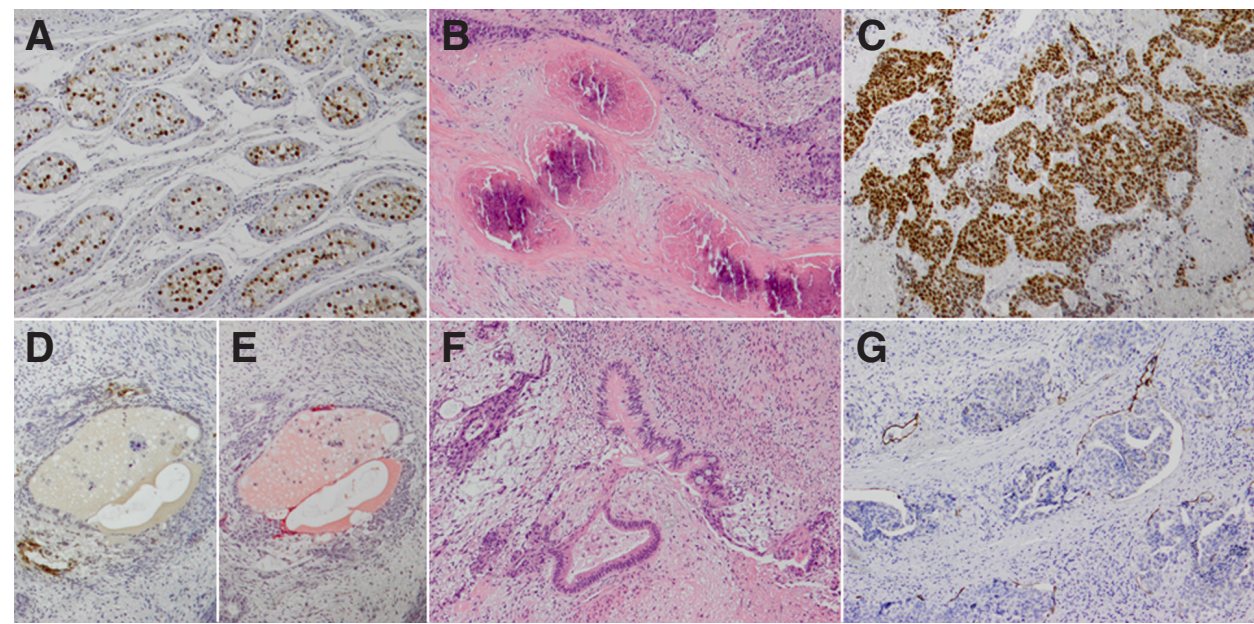

Fig. 1. Histology of orchidectomy specimen demonstrating progression from precursor lesion carcinoma in situ (CIS), to angioinvasiveness. (A) C/S (OCT3/4); (B) necrotizing intratubularnon-seminoma (H\&E); (C) embryonal carcinoma (OCT3/4); (D) yolk sac elements (AFP); (E) trophoblastic giant cells (HCG); (F) teratoma with glands and mesenchymal tissue (H\&E); (G) invasion of lymphatics by embryonal carcinoma (D2-40). (Original magnification of all photographs x50) (Immunohistochemistry was carried out using routine procedures and commercially available antibodies as described (Looijenga et al., 2003). out-patient clinic. In October 1990, five months after orchidectomy, the CT-scan of the chest and abdomen showed multiple enlarged retroperitoneal, para-aortic and retro-crural lymph nodes with a maximum size of $2 \mathrm{~cm}$, classifying it as a stage III non-seminoma. According to the international germ cell consensus classification (IGCCC, 1997) the patient had a favorable prognosis since he only had non-pulmonary, non-visceral metastases and normal levels of APF and B-HCG. He was treated with three courses of bleomycin, etoposide, and cisplatin and one course of etoposide
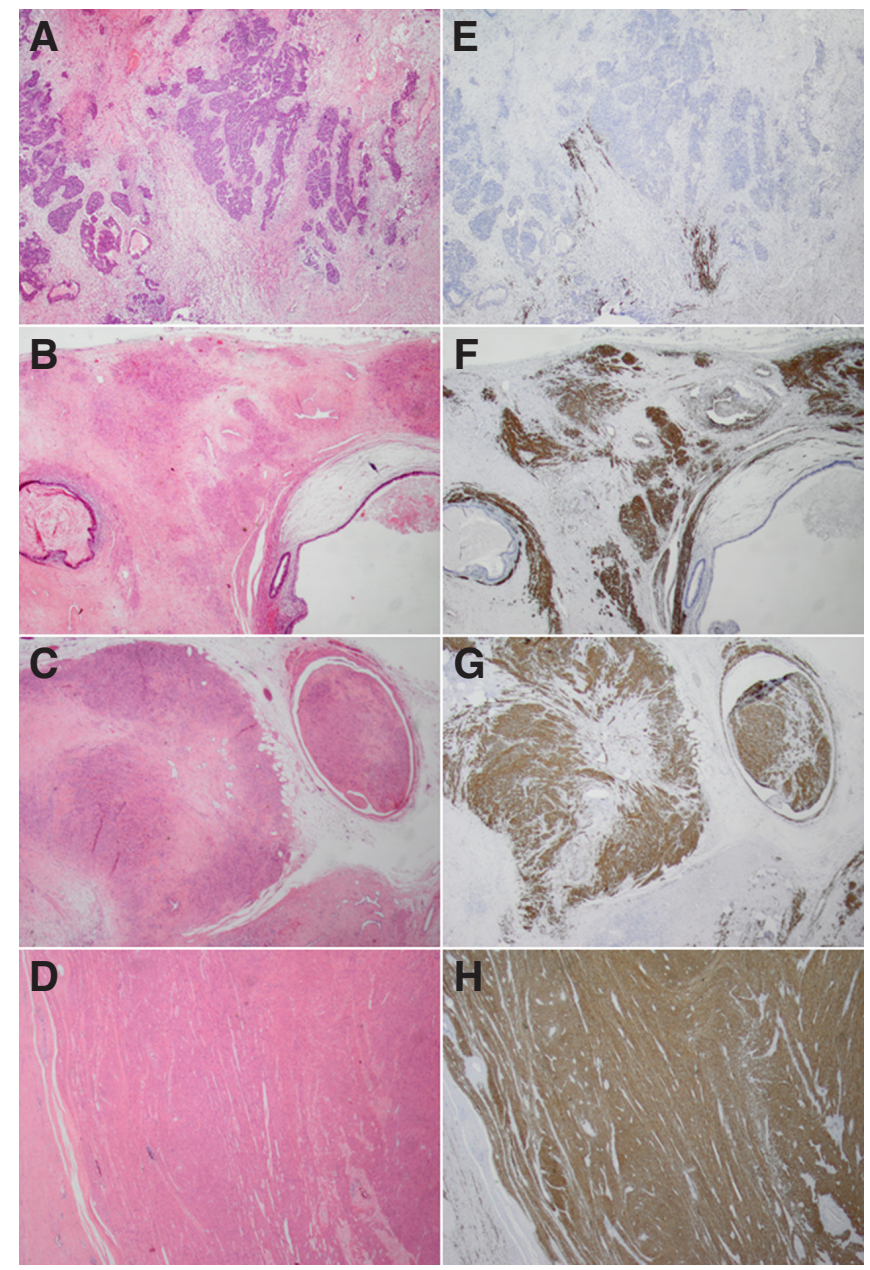

and cisplatin according to EORTC trial 30824 , resulting in complete resolution of retro-crural lymph node lesions, but persistence of para-aortic nodes (maximum size of $1.5 \mathrm{~cm}$ ). February 1991, four months after chemotherapy, a retroperitoneal lymph node dissection (RPLND) was performed.

Histo-pathological examination of the 16 removed lymph nodes revealed in three of them residual mature teratoma embedded in reactive fibrous tissue. There were no cKIT-positive stromal cells. The amount of smooth muscle relative to other components in the recurrence (Fig. 2 B,F) had increased as compared to the primary tumor (Fig. $2 \mathrm{~A}, \mathrm{E}$ ). None of the tissues met the criteria of a secondary somatic-type malignancy.

In November 1991, four months after RPLND, the retro-crural, mediastinal lymph nodes started to increase in size. AFP and B$\mathrm{HCG}$ were in the normal range. A surgical resection was proposed, however, the patient decided to postpone thoracic surgery. One year later, in April 1992, multiple enlarged mediastinal nodes (largest dimension $3 \mathrm{~cm}$ ) were resected. Histology of the resected mediastinal lymph nodes showed metastatic tumor tissue, at the time diagnosed as mature teratoma (Fig. $2 \mathrm{C}, \mathrm{G}$ ). In the following five years no abnormalities were detected. Serum AFP and B$\mathrm{HCG}$ remained normal and CT-scans of chest and abdomen did not reveal abnormalities, consistent with a complete remission of his metastatic non-seminoma. The patient remained in follow-up thereafter with serum levels of AFP and B-HCG being measured every three months, but no more CT scans.

In September 2009, 19 years after the initial diagnosis, the patient presented with abdominal pain. CT scan revealed a new retroperitoneal mass of $13.4 \mathrm{~cm} \times 11.9 \mathrm{~cm} \times 6.0 \mathrm{~cm}$. AFP and $\mathrm{B}-\mathrm{HCG}$ were in the normal range. PET scan showed slight positivity in the retroperitoneal mass, indicating active disease. Complete removal of the lymphatic tissue and tumor mass in the retroperitoneum was attempted and followed by a single round of bleomycin, etoposide en cisplatin chemotherapy.

Fig. 2. Smooth muscle component in primary tumor and recurrences. Smooth muscle, a minor component in the primary tumor (A)H\&E, (E) desmin, is clearly increasing in the first (B) $H \& E,(\mathbf{F})$ desmin and second recurrence (C) $H \& E,(\mathbf{G})$ desmin, and constitutes over $90 \%$ in the third recurrence (D) $H \& E,(\mathbf{H})$ desmin. Note the infiltrative borders and the angio-invasion of the smooth muscle component of the second recurrence $(\mathbf{C , G )}$ (original magnification of all photographs $\times 12,5)$. 
Histo-pathological examination of the retroperitoneal mass showed small areas with the usual pattern of mature teratoma with cysts and glands lined by well differentiated epithelium of various types, and surrounded by smooth muscle and fibrous tissue in concentric layers in an organoid arrangement. However, some glands and cysts showed mildly dysplastic epithelium with overlapping nuclei (Fig. 3D, left side) and also with frankly malignant characteristics: hyperchromatic, pleomorphic nuclei and mitotic figures, justifying the diagnosis of an intestinal-type adenocarcinoma (Fig. 3D, right side). Immunohistochemically the adenocarcinoma cells were positive for CK20 and CDX2, and negative for AFP, ruling out the possibility of a glandular yolk sac tumor. Remarkably, large areas of the tumor were composed of smooth muscle tissue (desmin-positive, cKIT-negative) with mildly atypical cyto-nuclear features, however clearly growing expansively

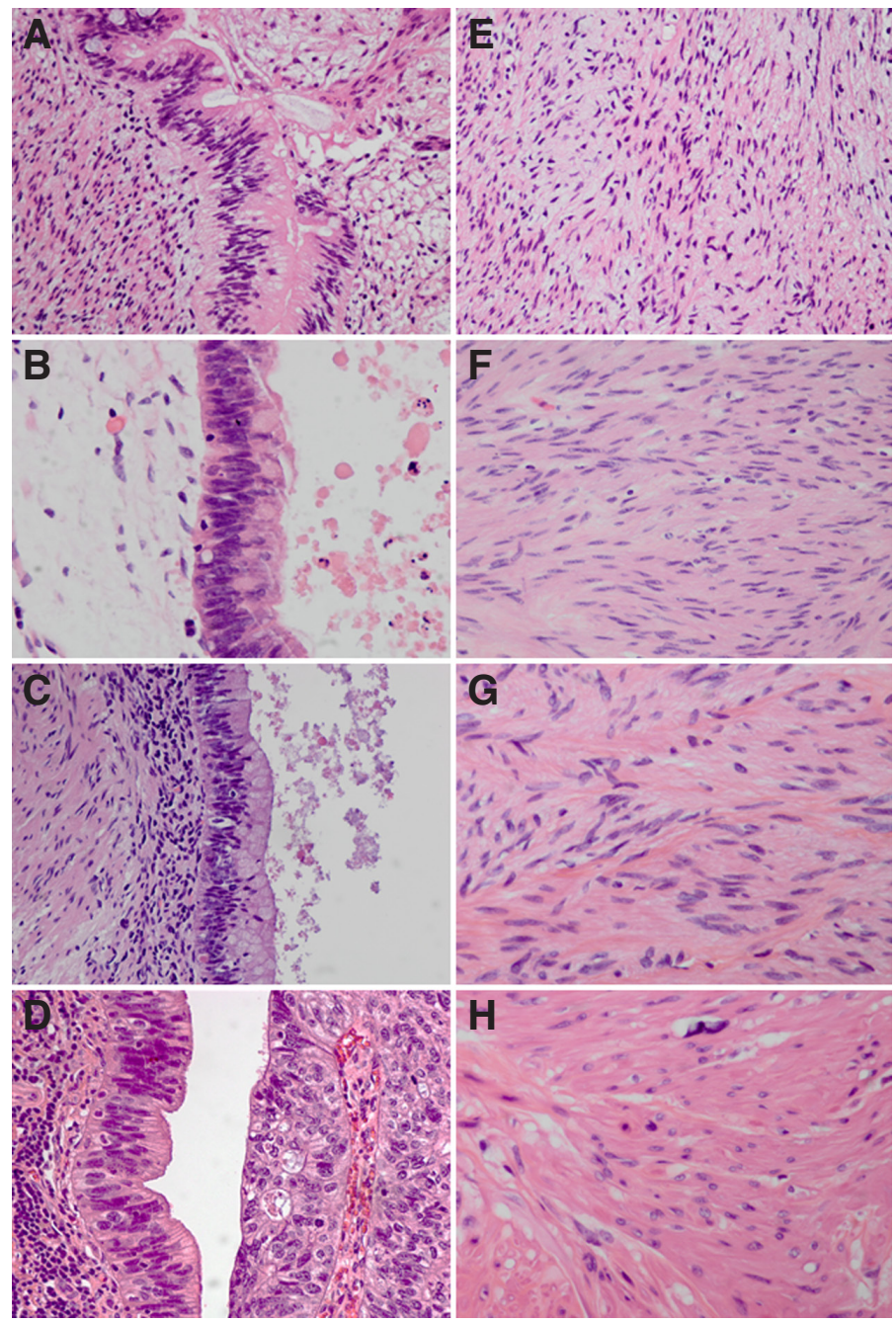

Fig. 3. Development of intestinal type adenocarcinoma and low grade leiomyosarcoma over a 19-year period. In the primary tumor are glands lined by mildly dysplastic glands with overlapping nuclei (A). Similar epithelium is also present in the first (B), second (C) and third recurrence (D), left side of photograph). In addition there is intestinal-type adenocarcinoma present in the third recurrence (D, right side of photograph). There is a gradual increase of cyto-nuclear atypia in the smooth muscle component of the primary tumor $(\mathbf{E})$, the first $(\mathbf{F})$, second $(\mathbf{G})$ and third recurrence $(\mathbf{H})$. (H\&E; original magnification of all photographs $\times 200$ ). and invasively, sometimes into vessels (Fig. $2 \mathrm{D}, \mathrm{H}$ ). In retrospect this component was already present in the metastases removed 17 years earlier, in April 1992. In fact, angio-invasiveness of this component was more prominent at that time (Fig. 2 C,G). The solid smooth muscle component (desmin-positive, cKIT-negative) was also present in the first lymph node dissection of February 1991 (Fig. $2 \mathrm{~B}, \mathrm{~F}$ ), and in the primary tumor (Fig. $2 \mathrm{~A}, \mathrm{E})$. Thus, the histological diagnosis was made of mature teratoma with progression towards somatic-type malignancy in two different lineages: intestinal-type adenocarcinoma and a low grade leiomyosarcoma. In Fig. 3 the progression of the cyto-nuclear atypia of both the epithelial (Fig. $3 \mathrm{~A}-\mathrm{D}$ ) and the smooth muscle lineage (Fig. $3 \mathrm{E}-\mathrm{H}$ ) is shown. In the mildly dysplastic epithelium there is no clear progression, only in the late recurrence (Fig. 3D) there is sudden progression towards adenocarcinoma. In the smooth muscle component there is a gradual progression of the cyto-nuclear atypia. Radiographic evidence of persistent disease was detected three months after the last surgery. A small residual lesion $(1.7 \mathrm{~cm})$ surrounding the clips of the operation and small retroperitoneal lymph nodes have remained unchanged during follow-up so far. Follow-up of tumor markers and CT is scheduled every three months. The patient is still in good condition, alive with disease at 21 years after the detection of the primary tumor.

\section{Discussion}

The story of this patient is familiar to clinicians: presentation with a primary testicular mixed non-seminoma with a teratoma component; residual mature teratoma (RMT) after chemotherapy of retroperitoneal metastases discovered within a year of followup (Loehrer et al., 1986). Early on we demonstrated that RMT is virtually always associated with primary tumors with a teratoma component (Oosterhuis, 1983), like in this case. Late recurrences, appearing after many years, harboring a secondary malignancy are also well established (Molenaar et al., 1986, Ulbright et al., 1984). As these recurrences do not give rise to increased levels of AFP and/or B-HCG in serum, appropriate clinical follow-up should include routine physical examination and radiological imaging (Carver et al., 2007, Krege et al., 2008). As for therapy: there is little doubt that treatment with curative intent entails radical surgery of persistent disease (Carver et al., 2007, Comiter et al., 1998, Krege et al., 2008).

Somatic-type malignancies occur in primary testicular nonseminomas in 3\% to 6\% (Guo et al., 2009), in postchemotherapy RPLND in $8 \%$ (Carver et al., 2007). In late recurrences the percentage is over 20 (Michael et al., 2000). The most common types of somatic-type malignancies are sarcomas, over half of the patients have a sarcoma (Motzer et al., 1998). The most frequent types are rhabdomyosarcoma, followed by angiosarcoma and leiomyosarcoma (Malagon et al., 2007). Next in frequency are carcinoma's of various types and small blue round cell tumors (Comiter etal., 1998, Ganjoo etal., 2001, Guo et al., 2009, Malagon et al., 2007, Michael et al., 1997, Motzer et al., 1998). The occurrence of two types of secondary somatic type malignancies in late recurrences is rare, but has been reported earlier (Comiter et al., 1998). To the best of our knowledge the combination of an epithelial (intestinal-type adenocarcinoma), and a mesenchymal (low grade leiomyosarcoma) in the late recurrence has not been published before. 
Ulbright et al., were the first to demonstrate that the secondary malignancy can often be demonstrated in the primary tumor already (Ulbright et al., 1984). In retrospect the glands with mild dysplasia, characterized by slightly enlarged, overlapping nuclei and the smooth muscle component in the primary tumor are likely the precursors of the adenocarcinoma and the low grade leiomyosarcoma identified in the following recurrences, although at the time of presentation they did not meet the criteria of a secondary somatic-type malignancy. It is apparently hard to predict the development of somatic-type malignancies from the histology of the primary non-seminoma. In particular the distinction between focal stromal proliferations and sarcomatous components may be difficult (Wiland et al., 2010). If the sarcoma component is confined to the primary tumor, it does not seem to adversely affect the prognosis of the patient (Guo et al., 2009). Likewise a primitive neuroectodermal tumor localized to the testis does not affect prognosis (Michael et al., 1997).

The intestinal adenocarcinoma was not present in the primary tumor and the two early recurrences. It has, therefore, most likely developed from the mildly dysplastic epithelium present in the third recurrence. This phenomenon has been described before (Molenaar et al., 1986, Ulbright et al., 1984). Thus the present case combines the two ways by which secondary somatic-type malignancies may develop: due to progression in a teratoma component, already in the primary tumor, or in a metastatic lesion.

One cannot exclude that chemotherapy contributes to the development of secondary somatic-type malignancies. However, the fact that they are quite often already present in the primary tumor argues against this assumption. The development of secondary somatic-type malignancies is more likely due to spontaneous progression of the near-triploid (Oosterhuis et al., 1989), chromosomally instable, teratoma cells. There is an analogy here with the "normalization" of embryonal carcinoma cells in chimeric mice. Embryonal carcinoma cells with too many chromosomal/ genetic aberrations may contribute to seemingly normal tissues of the mice, but also give rise to tumors (Papaioannou and Rossant, 1983). When embryonal carcinoma cells differentiate into somatic lineages the cyto-nuclear characteristics of the tumor cells normalize. However, the somatic cells can escape normalization, and progress towards secondary somatic-type malignancies. Somatic-type malignancies could thus be viewed as failures of normalization of cancer by developmental patterning due to cancer cell autonomous forces overruling normalizing cell-community effects (Levin, 2012).

Because the teratoma component and secondary somatic-type malignancies derived thereof are resistant to the cisplatin-based chemotherapy to which the other components are sensitive, they are "enriched" in residual tumor and recurrences after chemotherapy (Mayer et al., 2003).

It is interesting to look at this process from the perspective of the cancer stem cell hypothesis. It predicts that when cancer stem cells, the clonogenic cells of a cancer, can be specifically targeted cancers could be treated effectively, because their more differentiated, non-clonogenic daughter-cells will eventually disappear (Dean et al., 2005, Reya et al., 2001). It is well established that embryonal carcinoma cells are the stem cells of non-seminomas. Both in mouse models and human non-seminomas it appears that the embryonal carcinoma cells are the clonogenic cells from which the other lineages, both extra-embryonic and embryonic, are derived (Andrews et al., 1984, Damjanov, 1990), and that they are sensitive to cisplatin (Oosterhuis et al., 1984). In germ cell tumors the yolk sac and the trophoblastic lineage disappear as predicted. However somatic tissues (teratoma) often survive chemotherapy. Why this difference between the extra-embryonic and the embryonic lineages? It is tempting to speculate that somatic differentiation requires the development of several layers of committed progenitor cells and ultimately adult stem cells, which have been demonstrated to be more resistant to chemotherapy (Dean et al., 2005). The stem cells of the extra-embryonic tissues are probably the embryonal carcinoma cells themselves or stem cells with a similar sensitivity to cisplatin as embryonal carcinoma cells. These tissues are short-lived "disposables" for which the types of resistant stem cells of the long-lived somatic tissues are probably not required. The different fate of embryonal carcinoma and the extra-embryonic lineages on the one hand and the teratoma component on the other, is also demonstrated in the present case: the former have not re-appeared after chemotherapy in 1991, and consistent with the histological findings, serum AFP and B-HCG have remained normal. Only the teratoma component has survived chemotherapy, and has progressed to somatic-type malignancies, which remain a serious threat to the patient, if they cannot be radically resected. The favorable response of the stem cell component and its immediate derivatives, the extra-embryonic tissues, is what cancer stem cell therapy promises to achieve. However, the behavior of the teratoma component cautions against too much optimism. Surviving cancer cells, even when all cancer stem cells could be destroyed, may eventually progress and acquire clonogenic capacity, similar to the development of the secondary somatic-type malignancies from teratoma components in the present case.

Yet another contention of the cancer stem cell hypothesis can be illustrated from this patient. Cancer stem cells are supposed to be the cancer cells with metastatic potential. They are clonogenic and may undergo epithelial-mesenchymal transition and vice versa (Brabletz et al., 2005). Thus these cells are the "decathlon winners" (Fidler, 2003, Hanahan and Weinberg, 2011), that can enter vessels, home in suitable soil, and establish new colonies, in which the various differentiation lineages of the primary tumor can reappear. The primary testicular tumor of the present patient showed extensive angio-invasion. The tumor cells in the vessels were exclusively embryonal carcinoma cells, the cancer stem cells of non-seminomas. Indeed, in non-seminomas tumor emboli, be it in blood vessels or lymphatics, are virtually always exclusively composed of embryonal carcinoma cells (Ulbright et al., 1997). Apparently the metastatic embryonal carcinoma cells can differentiate into the various lineages once arrived at a metastatic site. Using a re-transplantable mouse teratocarcinoma that gives rise to lymph node metastasis we have shown that this is in fact the case. The first tumor cells tumor cells detectable in the sinus of the regional lymph nodes are embryonal carcinoma cells, which henceforth start to differentiate into various lineages, amongst others teratoma (Oosterhuis, 1983).

In summary, this case-report describes some of the pitfalls of follow-up and treatment of testicular non-seminomas, and the rare simultaneous development of two secondary somatic-type malignancies. This, and similar cases, illustrate normalization of cancer by developmental patterning, and provide insight into the potential and flaw of cancer stem cell therapy, as cisplatin-based 
chemotherapy of non-seminomas can be viewed as cancer stem cell therapy avant la lettre.

\section{Acknowledgements} Martin Rijlaarsdam is acknowledged for his help in making the figures.

\section{References}

ANDREWS, P.W., DAMJANOV, I., SIMON, D., BANTING, G.S., CARLIN, C., DRACOPOLI, N.C. and FOGH, J. (1984). Pluripotent embryonal carcinoma clones derived from the human teratocarcinoma cell line Tera-2. Differentiation in vivo and in vitro. Lab Invest 50: 147-162.

BRABLETZ, T., JUNG, A., SPADERNA, S., HLUBEK, F. and KIRCHNER, T. (2005). Opinion: migrating cancer stem cells - an integrated concept of malignant tumour progression. Nat Rev Cancer 5: 744-749.

CARVER, B.S., SHAYEGAN, B., SERIO, A., MOTZER, R.J., BOSL, G.J. and SHEINFELD, J. (2007). Long-term clinical outcome after postchemotherapy retroperitoneal lymph node dissection in men with residual teratoma. J Clin Oncol 25: 1033-1037.

COMITER, C.V., KIBEL, A.S., RICHIE, J.P., NUCCI, M.R. and RENSHAW, A.A. (1998). Prognostic features of teratomas with malignant transformation: a clinicopathological study of 21 cases. J Urol 159: 859-863.

DAMJANOV, I. (1990). Teratocarcinoma stem cells. Cancer Surv. 9: 303-320.

DEAN, M., FOJO, T. and BATES, S. (2005). Tumour stem cells and drug resistance. Nat Rev Cancer 5: 275-284.

FIDLER, I.J. (2003). The pathogenesis of cancer metastasis: the 'seed and soil' hypothesis revisited. Nat Rev Cancer 3: 453-458.

GANJOO, K.N., FOSTER, R.S., MICHAEL, H., DONOHUE, J.P. and EINHORN, L.H. (2001). Germ cell tumor associated primitive neuroectodermal tumors. J Urol 165: 1514-1516.

GUO, C.C., PUNAR, M., CONTRERAS, A.L., TU, S.M., PISTERS, L., TAMBOLI, P. and CZERNIAK, B. (2009). Testicular germ cell tumors with sarcomatous components: an analysis of 33 cases. Am J Surg Pathol 33: 1173-1178.

HANAHAN, D. and WEINBERG, R.A. (2011). Hallmarks of cancer: the next generation. Cell 144: 646-674.

IGCCC. (1997). International Germ Cell Consensus Classification: a prognostic factor- based staging system for metastatic germ cell cancers. International Germ Cell Cancer Collaborative Group [see comments]. J Clin Oncol 15: 594-603.

KREGE, S., BEYER, J., SOUCHON, R., ALBERS, P., ALBRECHT, W., ALGABA, F., BAMBERG, M., BODROGI, I., BOKEMEYER, C., CAVALLIN-STAHL, E. et al., (2008). European Consensus Conference on Diagnosis and Treatment of Germ Cell Cancer: A Report of the Second Meeting of the European Germ Cell Cancer Consensus Group (EGCCCG): Part II. Eur Urol 53: 497-513.

LEVIN, M. (2012). Morphogenetic fields in embryogenesis, regeneration, and cancer: Non-local control of complex patterning. Biosystems 109: 243-261.

LOEHRER, P.J., HUI, S., CLARK, S., SEAL, M., EINHORN, L.H., WILLIAMS, S.D., ULBRIGHT, T.M., MANDELBAUM, I., ROWLAND, R.G. and DONOHUE, J.P. (1986). Teratoma following cisplatin-based combination chemotherapy for nonseminomatous germ cell tumors: a clinicopathological correlation. J.Urol. 135: 1183-1189.

LOOIJENGA, L.H.J., STOOP, H., DE LEEUW, P.J.C., DE GOUVEIA BRAZAO, C.A., GILLIS, A.J.M., VAN ROOZENDAAL, K.E.P., VAN ZOELEN, E.J.J., WEBER,
R.F.A., WOLFFENBUTTEL, K.P., VAN DEKKEN, H. et al., (2003). POU5F1 (OCT3/4) identifies cells with pluripotent potential in human germ cell tumors. Cancer Res 63: 2244-2250.

MALAGON, H.D., VALDEZ, A.M., MORAN, C.A. and SUSTER, S. (2007). Germ cell tumors with sarcomatous components: a clinicopathologic and immunohistochemical study of 46 cases. Am J Surg Pathol 31: 1356-1362.

MAYER, F., STOOP, H., SCHEFFER, G.L., SCHEPER, R., OOSTERHUIS, J.W., LOOIJENGA, L.H. and BOKEMEYER, C. (2003). Molecular determinants of treatment response in human germ cell tumors. Clin Cancer Res 9: 767-773.

MICHAEL, H., HULL, M.T., ULBRIGHT, T.M., FOSTER, R.S. and MILLER, K.D. (1997). Primitive neuroectodermal tumors arising in testicular germ cell neoplasms. Am J Surg Pathol 21: 896-904.

MICHAEL, H., LUCIA, J., FOSTER, R.S. and ULBRIGHT, T.M. (2000). The pathology of late recurrence of testicular germ cell tumors. Am J Surg Pathol 24: 257-273.

MOLENAAR, W.M., OOSTERHUIS, J.W., MEIRING, A., SLEIJFER, D.T., SCHRAFFORDT KOOPS, H. and CORNELISSE, C.J. (1986). Histology and DNA contents of a secondary malignancy arising in a mature residual lesion six years after chemotherapy for a disseminated onseminomatous testicular tumor. Cancer 58: 264-268.

MOTZER, R.J., AMSTERDAM, A., PRIETO, V., SHEINDELD, J., MURTY, V.V.V.S., MAZUMDAR, M., BOSL, G.J., CHAGANTI, R.S.K. and REUTER, V.E. (1998). Teratoma with malignant tansformation: diverse malignant histologies arising in men with germ cell tumors. J Urol 159: 133-138.

OOSTERHUIS, J.W. (1983). The metastasis of human teratomas. In The human teratomas, (ed. DAMJANOV, I.KNOWLES, B. and SOLTER, D.). Humana Press, Clifton, New Jersey, pp.137-171.

OOSTERHUIS, J.W., ANDREWS, P.W., KNOWLES, B.B. and DAMJANOV, I. (1984). Effects of cis-platinum on embryonal carcinoma cell lines in vitro. Int $J$ Cancer 34: 133-139.

OOSTERHUIS, J.W., CASTEDO, S.M.M.J., DE JONG, B., CORNELISSE, C.J., DAM, A., SLEIJFER, D.T. and SCHRAFFORDT KOOPS, H. (1989). Ploidy of primary germ cell tumors of the testis. Pathogenetic and clinical relevance. $L a b$ Invest 60: 14-20.

PAPAIOANNOU, V.E. and ROSSANT, J. (1983). Effects of the embryonic environment on proliferation and differentiation of embryonal carcinoma cells. Cancer Surv 2: 165-183.

REYA, T., MORRISON, S.J., CLARKE, M.F. and WEISSMAN, I.L. (2001). Stem cells, cancer, and cancer stem cells. Nature 414: 105-111.

ULBRIGHT, T.M., AMIN, M.B. and YOUNG, R.H. (1997). Tumors of the testis, adnexa, spermatic cord, and scrotum. AFIP, Washington.

ULBRIGHT, T.M., LOEHRER, P.J., ROTH, L.M., EINHORN, L.H., WILLIAMS, S.D. and CLARK, S.A. (1984). The development of non-germ cell malignancies within germ cell tumors. Cancer 54: 1824-1833.

WILAND, H.O., PAVLIDAKEY, P.G. and MACLENNAN, G.T. (2010). Nongerm cell malignancies in testicular germ cell tumors. J Urol 183: 327-328.

WOODWARD, P.J., HEIDENREICH, A., LOOIJENGA, L.H.J., OOSTERHUIS, J.W., MCLEOD, D.G. and MOLLER, H. (2004). Testicular germ cell tumors. In World Health Organization Classification of Tumours. Pathology and Genetics of the Urinary System and Male Genital Organs., (ed. EBLE, J. N.SAUTER, G.EPSTEIN, J. I. and SESTERHANN, I. A.). IARC Press, Lyon, pp.217-278. 


\section{Further Related Reading, published previously in the Int. J. Dev. Biol.}

Signaling pathways during maintenance and definitive endoderm differentiation of embryonic stem cells

Lina Sui, Luc Bouwens and Josué K. Mfopou

Int. J. Dev. Biol. (2013) 57: 1-12

Rediscovering pluripotency: from teratocarcinomas to embryonic stem cells

Ivana Barbaric and Neil J. Harrison

Int. J. Dev. Biol. (2012) 56: 197-206

Epiblast-derived stem cells in embryonic and adult tissues

Maria P. De-Miguel, Francisco Arnalich-Montiel, Pilar Lopez-Iglesias, Alejandro BlazquezMartinez and Manuel Nistal

Int. J. Dev. Biol. (2009) 53: 1529-1540

A novel, neural potential of non-hematopoietic human umbilical cord blood stem cells Krystyna Domanska-Janik, Leonora Buzanska and Barbara Lukomska

Int. J. Dev. Biol. (2008) 52: 237-248

Germinal tumor invasion and the role of the testicular stroma

Alejandro Díez-Torre, Unai Silván, Olivier De Wever, Erik Bruyneel, Marc Mareel and Juan Aréchaga

Int. J. Dev. Biol. (2004) 48: 545-557

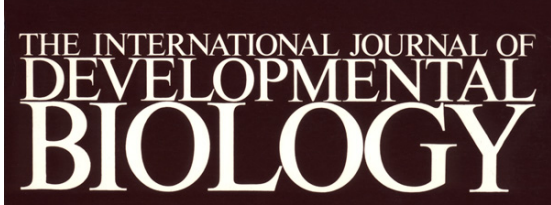

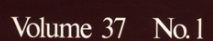

March 1993

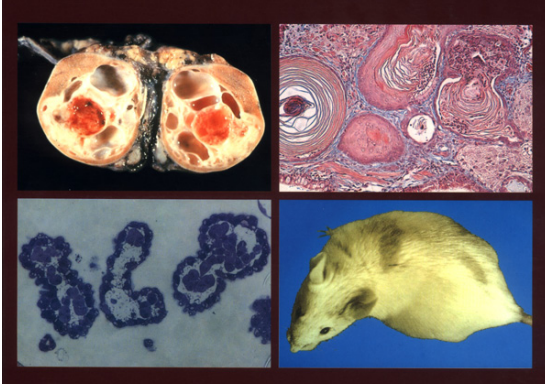

Developmental Aspects of Neoplasia
5 yr ISI Impact Factor $(2011)=2.959$

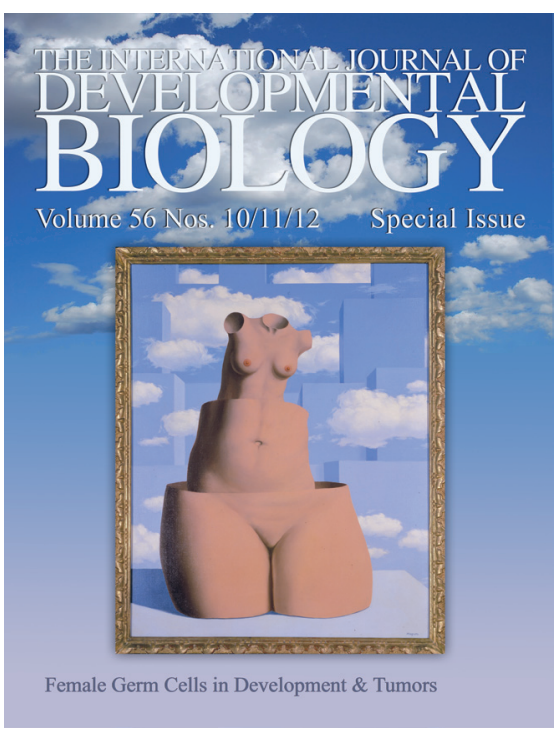

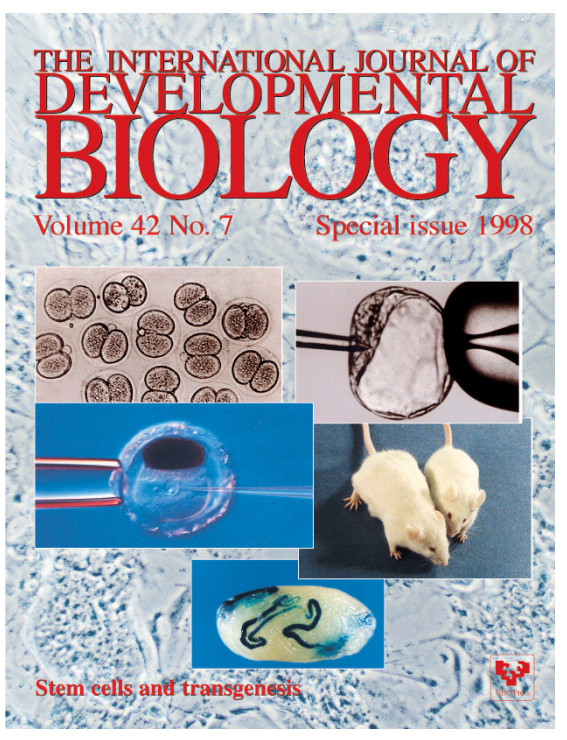

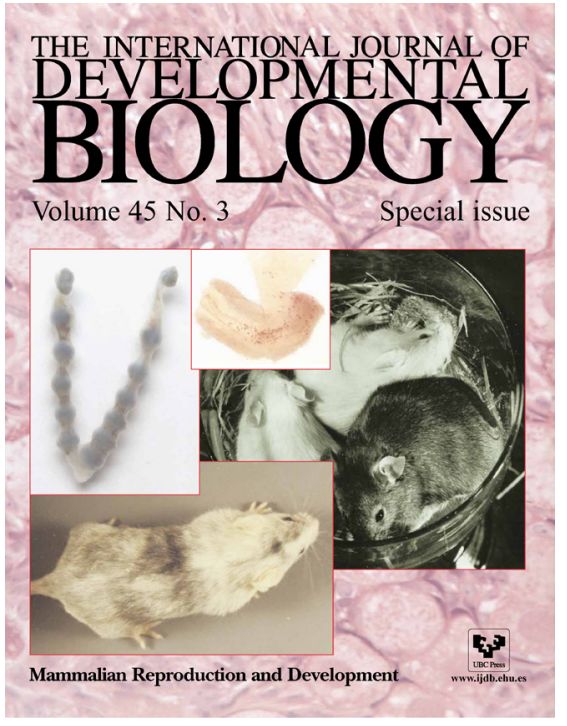

